\title{
Mini-Midline a New Device for Peripheral Venous Catheterization UN Emergency Wards
}

\author{
Morosini Irisneida ${ }^{1}$, Lucenti Enrico ${ }^{2}$, Mozzarelli Fabio ${ }^{3 *}$ and Raffo Emiliano ${ }^{4}$ \\ ${ }^{1}$ Nurse, Piacenza Hospital Guglielmo da Saliceto, Italy \\ ${ }^{2}$ Clinical Nurse Specialist in Emergency, Mecical System in Piacenza, Italy \\ ${ }^{3}$ Head Nurse, Piacenza Hospital Guglielmo da Saliceto, Italy \\ ${ }^{4}$ Marketing and Comunication, Piacenza Hospital Guglielmo da Saliceto, Italy
}

Submission: February 28, 2018; Published: March 20, 2018

*Corresponding author: Mozzarelli Fabio, Head Nurse, Piacenza Hospital Guglielmo da Saliceto, Italy, Tel: +39339/7498073;

Email: F.Mozzarelli@ausl.pc.it

\begin{abstract}
Introduction: The long peripheral venous cannula known as "mini-midline" is a peripheral venous catheter, 6-15 centimetres long positioned in the superficial veins located on the arm or the forearm. The use of this device is suggested for some specific patients or when numerous attempts at peripheral venous cannulation have all failed.

Methods: Articles regarding the usual positioning of a peripheral venous catheter with respect to an ultrasound-guided application of a long cannula peripheral device have been taken into account.

Results: As highlighted by the medical literature concerned, long cannula peripheral venous catheters inserted via an ultrasound-guided application are suitable for a certain kind of patient because they drastically reduce the number of attempts.

Discussion: It has been proved that a mini-midline can be rather effective in emergency wards as well. With its swiftness and highly effective placement, mini-midline turns out to be very useful for those patients that need a sound and secure vascular access because of their highly critical situation.

Conclusion: Mini-midline, if implanted by fully qualified personnel, allows choosing more wisely the devices of venous catheterization, thus avoiding the improper use of other vascular devices like, for example, central venous catheters.
\end{abstract}

Keywords: Mini-midline; Peripheral venous access; Ultrasound; Suitability; Emergency ward

\section{Introduction}

Nurses are constantly looking for vessels for infusions, blood samples, catheterisms. Sometimes a few problems, depending on the patient and his/her venous patrimony, may arise. The traditional approach involving numerous attempts at finding the vein frustrates the nurse and brings pain to the patient (this can result in early or late complications, morbility and the reduction and deterioration of the available veins). The most recent technological developments have made now available many different devices, each one with their own distinctive materials, features and instructions. Lately, a new aid called "mini-midline" (or long peripheral cannula) has been brought onto the market. It looks like it could well surpass, as far as efficiency and effectiveness are concerned, the traditional cannulas. It is considered the evolution of the peripheral venous catheters currently in use.
With the use of ultrasound-guided venipuncture and insertion via the Seldinger technique, the cannulation zone has moved from the antecubital fossa to the deep veins in the central part of the arm. This has positively increased the chances for this manoeuvre to be successful and bring fewer complications at the same time. This device includes an eco-reflecting introducer needle, a guidewire, and finally a polyurethane (or polyethylene) catheter that, with a little difference in level, allows the guide to pass. With no complications involved, this new catheter may remain in the same position for up to 30 days. This device has been thought out for those hospitalized patients to whom an implant for a central venous access is not recommended, but need a venous access for 10 or more days. Mini-midline is recommended to patients that, for many different reasons (clinical situation, age, underlying 
diseases, insufficient venous patrimony, issues related to the length of the therapy and all the possible complications connected to the therapy itself), need a peripheral device that should not lose its original position for many days to come $[1,2]$.

As far as the placement is concerned, the aid of a small-probe ultrasound machine necessary for two reasons: to find the vase that must be cannulated and make the insertion of the needle in the catheter easier (easy to check as well). This process is frequently used in order to correctly place long peripheral venous catheters and mid-term ones [3]. This new system prevents the ones using it from wrongly applying a central way. Thanks to its length, it ensures that just a few dislocation-related risks will be actually taken. This new system prevents the user from resorting to the improper use of a central way, and thanks to its length, it ensures the risks of dislocation, or those complications that usually show up with traditional short cannulas (burst/broken blood vessel, thrombotic risk, extravasation), are reduced. It must be added that the device is made of polyurethane, a material both flexible and biocompatible. This essay intends to verify the diverse and flexible ways of usage of this very device. Even in emergency units.

\section{Methods}

Recent Italian studies evaluating the use of long cannulas for certain groups of patients (obese people, patients with chronical diseases or dehydrated, people with a parental drug-addiction history or, more frequently, with a scarce venous patrimony or considered "difficult" because it can be quite hard to reach their vascular access via a blind procedure) have revealed good performance results, for example the number of attempts at getting to an ultrasound-guided access. Regarding that, the authors have recorded just 1, 57 attempts with an average execution time of 9,5 minutes. In $73 \%$ of patients, the acquired venous way has been maintained for more than 7 days. In this study, infective or thrombotic complications depending on the use of long polyurethane venous catheters have not been reported [4].

The application of a polyurethane arterial catheter placed in deep venous vases with the ultrasound-guided Seldinger technique has been considered by another observational study, though. The devices have been applied to in-patients of the intensive care unit. The results have turned out to be $100 \%$ successful and the device has been maintained for 7 days. Infective complications (even thrombophlebitis or haematic extravasation) have not been detected [5]. A further scientific system revision via meta-analysis, in which the authors have considered some trials concerning the blind venous cannulation, has revealed that echo-guided applications are more successful than the ultrasound-guided ones. (OR 2.42; 95\% CI 1.26-4.68; p=0.008) [6]. An American study has compared the results concerning standard venous cannulations with the ones obtained by the same personnel after specific training and the compliance to specific guidelines regarding the echo-guided procedure. As the authors have noted, the success of cannulations has increased of $10 \%$, complications have decreased by $23,3 \%$, the number of attempts has been reduced (1.6 vs 3.6; 95\% CI 1.6 - 2.7) and the satisfaction of the patient has remarkably increased $(p=0.0001)$ [7].

\section{Discussion}

The "mini-midline" peripheral venous catheter, showing easiness and swiftness when the implant is echo-guided via the Seldinger technique, is bound to become an operational procedure that can be used in first aid and other emergency units. The effortless management of this long peripheral cannula allows obtaining, in a short period of time, a steady and efficient venous access. The aforementioned device can guarantee more safety for patients, reducing the complications and obtaining a better cost-effective relationship. The ultrasound aid that traces peripheral venous accesses finds the ideal ally in those patients showing an impoverishment of the vascular patrimony. The echoguided search for deep vases and the insertion, via the Seldinger technique, brings a remarkable reduction of unsuccessful attempts and, at the same time, allows overused veins "to get some rest". This is specifically thought for obese patients and for either those ones subject to a prolonged endovenous therapy or those treated with irritant chemicals [8] (patients receiving chemiotherapy, for example). The ongoing technologic evolution is heading towards increasingly smaller tools and specific personnel trainings. This allows the development of the echo-guided technique, which is essential to reach vases. Nurses should not be exempted from this process [9-14].

\section{Conclusions}

Thanks to this new long peripheral cannula, echo-guided venipuncture of deep veins and the embracement of the Seldinger technique guarantee a major percentage of successes for this very manoeuvre, bringing a reduction of early and late complications and an increase of the comfort of the patient as the pain decreases after one single venipuncture, thus limiting the number of blind attempts. With this procedure, a reduction of the management times required for each single patient can be observed. Thanks to the simplicity of its use, it is particularly suitable for first aid units and emergency wards and in settings like surgeon and palliative care areas as well. To use it properly, it is necessary to define the right clinical care situation, as well as those features of the patient that inevitably point to "mini-midline" as the device of choice. A well-thought evaluation on how the device must be used (thanks to the low cost and the lasting placement in situ), make "minimidline" a promising device that clearly stands out if compared to the other available devices.

\section{Conflicts of Interest}

None.

\section{References}

1. Rabbia C, De Lucchi R, Cirillo R (1999) Eco Color-Doppler Vascolare, Minerva Medica, Torino, Italy.

2. Reichman EF, Simon RR (2007) Emergency Medicine Procedures. McGraw Hill, New York, USA. 
3. Rivera SA (2005) Cateterismo venoso periferico. In: Parra Moreno NL, et al. (Eds.), Il paziente critico, Masson, Milano, Italy.

4. Scoppettuolo G, Pittiruti M, Pitoni S, Laura D, Alessandro E, et al. 2016) Ultrasound-guided short midline catheters for difficult venous access in the emergency department: a retrospective analisys. Int J Emerg Med 9(1): 3.

5. Meyer P, Cronier P, Rousseau H, Vicaut E, Choukroun G, et al. (2014) Difficult peripheral venous access: clinical evaluation of a catheter inserted with the Seldinger method under ultrasound guidance. J Crit Care 29(5): 823-827.

6. Bauman M, Braude D, Crandall C (2009) Ultrasound-guidance versus standard technique in difficult vascular access patients by ED technicians. Am J Emerg Med 27(2): 135-140.

7. Egan G, Healy D, O Neill H, Clarke Moloney M, Grace PA, et al. (2013) Ultrasound guidance for difficult peripheral venous access: systematic review and meta-analysis. Emerg Med J 30(7): 521-526.

8. (2003)Preventing IV therapy complications, part 1. Chemical phlebitis, Infusion partners, USA.

9. Nelson S, Armes S, Austin A (2008) Care and maintenance to reduce vascular access complications. Nursing Best Practice Guidelines.
Shaping the future of nursing. Registered Nurses' Association of Ontario.

10. Brennam L, Blaivas M, Lyon M, Flake M (2004) Emergency nurse utilisation of ultrasound guidance for placement of peripheral intravenous lines in difficult access patients. Acad Emerg Med 11: 1361-1363.

11. Blavias M, Lyon M (2006) The effect of ultrasound guidance on the perceived difficulty of emergency nurse obtained peripheral IV access. J Emerg Med 31(4): 407-410.

12. Chinnock B, Thornton S, Hendey GW (2007) Predictors of success in nurse performed ultrasound guided cannulation. J Emerg Med 33(4): 401-405.

13. Aponte H, Acosta S, Rigamonti D, Sylvia B, Austin P, et al. (2007) The use of ultrasound for placement of intravenous catheters. AANA J 75: 212-216.

14. Costantino TG, Parikh AK, Satz WA, Fojtik JP, et al. (2005) Ultrasonography guided peripheral intravenous access versus traditional approaches in patients with difficult intravenous access Ann Emerg Med 46(5): 456-461.
Your next submission with Juniper Publishers will reach you the below assets

- Quality Editorial service

- Swift Peer Review

- Reprints availability

- E-prints Service

- Manuscript Podcast for convenient understanding

- Global attainment for your research

- Manuscript accessibility in different formats

( Pdf, E-pub, Full Text, Audio)

- Unceasing customer service

Track the below URL for one-step submission https://juniperpublishers.com/online-submission.php 